\title{
CAcuaytaritiorio
}

\section{Evaluación del primer ciclo de planificación hidrológica en España en aplicación de la Directiva Marco del Agua}

\begin{abstract}
A la espera de publicar en el núm. 5 de Agua y Territorio la completa Evaluación del Primer Ciclo de Planificación Hidrológica en España en aplicación de la Directiva Marco del Agua (DMA), queremos incorporar en este núm. 4 las conclusiones de dicho Informe, que acaban de ser difundidas por el Observatorio de las Políticas del Agua (Fundación Nueva Cultura del Agua) y remitidas a la Comisión Europea para ser consideradas en la reunión que va a celebrar con el Gobierno de España este próximo 11 de noviembre de 2014
\end{abstract} [NOTA DE LOS EDITORES]

Se presentan a continuación las principales conclusiones del Informe de Evaluación del Primer Ciclo de Planificación Hidrológica en España en aplicación de la Directiva Marco del Agua (DMA), elaborado por el Observatorio de las Políticas del Agua (OPPA) de la Fundación Nueva Cultura del Agua (FNCA). Dicho informe sintetiza los principales resultados contenidos en un amplio conjunto de informes específicos sobre las distintas demarcaciones hidrográficas y sobre otras cuestiones transversales.

El informe de síntesis y los informes específicos en los que se basa están disponibles para su consulta en la página web: http:/ / bit. Iy/ 1zrEho0. Mientras que el informe de síntesis y este resumen ejecutivo son obra del OPPA, Ios informes individuales son responsabilidad de sus autores y no reflejan necesariamente la opinión de la FNCA.

\section{Resumen}

1. A pesar del tiempo transcurrido desde la aprobación de la DMA, su transposición al ordenamiento jurídico español sigue siendo incompleta e inadecuada, especialmente en lo relativo a coordinación interadministrativa (Comité de Autoridades Competentes), régimen económico financiero, definición de los objetivos de la planificación hidrológica y su relación con las estrategias y planes sectoriales.

2. La aprobación de los planes hidrológicos se ha retrasado al extremo de que su entrada en vigor tenga un carácter testimonial, lo que implica dar por perdido el primer ciclo de planificación.
3. Existen deficiencias graves de gobernanza, tanto por lo que se refiere al papel efectivo de coordinación del Comité de Autoridades Competentes como a los procesos de participación real del público y las partes interesadas en la planificación y gestión del agua. Los procesos de participación pública no han sido efectivos para influir en las cuestiones de calado, como la consecución de los objetivos ambientales, los programas de medidas y los costes. En ocasiones, aspectos cruciales que condicionan la gestión del agua y la obtención de los objetivos de la DMA, como es el caso del Trasvase TajoSegura, han sido directamente excluidos del proceso de planificación y participación pública.

4. En la mayor parte de las masas de agua la relación estado-presiones-obj etivos-medidas-resultados no se define de manera concreta y trazable. Así, en términos generales, no se analiza la relación entre la agricultura de regadío y el deterioro de las masas de agua ni se fijan objetivos cuantificados que permitan el seguimiento de la eficacia de las medidas.

5. Existe un gran número de masas sin definición de estado ecológico, carencias en el establecimiento de condiciones de referencia y falta de aplicación de indicadores clave requeridos por la DMA, como los de alteración hidrológica, alteración hidromorfológica o los relativos a peces.

6. Persisten muchas masas fluviales sin caudales ambientales establecidos. En los casos en los que se han fijado, los caudales ambientales no están vinculados al estado de las masas de agua. En la mayoría de demarcaciones la concertación de caudales ha sido insuficiente 0 inexistente. 
7. En la mayoría de las demarcaciones no aparecen objetivos específicos de conservación de las masas de los lugares Natura 2000, lo que incumple el artículo 4.1.c de la DMA y amenaza la conservación de tales espacios protegidos.

8. En buena parte de las demarcaciones se han aplicado prórrogas generalizadas para alcanzar el buen estado de las masas de agua, prórrogas que no están adecuadamente justificadas en base a costes desproporcionados, como requiere la DMA. En España se omite el carácter excepcional de la exención por nuevo deterioro de las aguas, se hace aún más evidente la ausencia de justificación adecuada y no se retrotrae la aplicación de dicha exención al menos a la fecha en que hubieran debido entrar en vigor los planes hidrológicos (22 de diciembre de 2009).

9. Los programas de medidas están condicionados por la herencia de políticas anteriores y siguen orientadas al fomento de obras para el incremento de la oferta y la satisfacción de las demandas, sobre todo el regadío, ajenas al objetivo de alcanzar y mantener el buen estado de las aguas. La mayor parte del presupuesto de los programas de medidas se asigna a estas obras mientras que a las medidas básicas ambientales se asignan presupuestos mucho más reducidos o testimoniales. Además, las medidas se han establecido sin una vinculación con los obj etivos ambientales a escala de masa de agua, sin la exigida evaluación coste-eficacia, sin evaluar su impacto sobre el estado ecológico de las masas y sin un calendario claro de ejecución y financiación.

10. La recuperación de costes se mantiene en niveles muy bajos. Además de no considerar costes ambientales y del recurso, se emplean artificios contables para rebajar la cuantía de los costes totales y aproximarla a lo repercutido, como aplicar descuentos en las obras de presas hidráulicas por su función de laminación de avenidas como forma de encubrir una subvención pública arbitraria. Por otra parte, dicha repercusión se realiza al margen del principio de quien contamina (deteriora) paga.

11. La insuficiente e inadecuada recuperación de costes tiene consecuencias importantes. Por un lado impide la consideración de alternativas más costo-eficientes que las adoptadas, por ejemplo en protección frente a avenidas; por otro, mantiene ocioso buena parte del parque de desaladoras construidas - con fondos europeos-en la costa mediterránea.

12. En la mayoría de las demarcaciones, los procedimientos de Evaluación Ambiental Estratégica (EAE) únicamente han planteado algunas alternativas genéricas a las medidas aprobadas que en la práctica no son tales, lo que desvirtúa los efectos reales de la EAE. Los procedimientos de EAE no han analizado las alternativas concretas de gestión para cada uno de los problemas clave de cada demarcación o los impactos de los planes sobre la Red Natura 2000.

13. La escasa o nula ambición a la hora de aplicar la Directiva y el mantenimiento de las viejas inercias de fomento de la obra hidráulica y satisfacción de las demandas quedan crudamente reflejados en casos tan relevantes como el Delta del Ebro, la Cuenca Alta del Guadiana, Doñana, I'Albufera de Valencia y el Estuario del Guadalquivir, lugares donde el incumplimiento de la DMA tiene importantes consecuencias negativas sobre estos espacios protegidos de la Red Natura 2000 y áreas Ramsar, de sobrada importancia ecológica y reconocimiento internacional.

14. En conclusión, el primer ciclo de planificación en el marco de la DMA se ha caracterizado en España por una incorporación retórica del lenguaje de la DMA sin aproximación conceptual y metodológica a la misma ni efectos prácticos reales. Pese a los esfuerzos políticos del Ministerio de Medio Ambiente en el periodo 2004-2008 y del compromiso de algunos técnicos en las Oficinas de Planificación de determinados organismos de cuenca, se ha procedido a una actualización de los planes tradicionales de satisfacción de las demandas y fomento de obras hidráulicas a la que se yuxtapone ahora -de manera necesariamente incoherente- un plan de "cumplimiento de los objetivos ambientales de la directiva", que no ha hecho variar las viejas inercias y, por tanto, no cumple la DMA.

15. En definitiva, el proceso de renovación de la política de aguas en España (2000-2014) resulta frustrante. En la primera generación de planes hidrológicos no hubo ocasión para la innovación debido a la premura final para aprobarlos antes de agotar su periodo de vigencia teórico (2015), manteniendo en líneas generales la orientación de los planes (de 1998) anteriores a la DMA. Los planes de la segunda generación (2015-2021), según declaraciones de los responsables de planificación, no incorporarán variaciones sustanciales puesto que se acaban de aprobar los anteriores. Así, si no se produce un cambio de rumbo radical, la política hidráulica del siglo XX se perpetuará en las dos primeras décadas del siglo XXI. 
